\section{AB0773 EFFECTIVENESS OF GOLIMUMAB IN TNF-INHIBITOR INADEQUATE RESPONDER PATIENTS WITH SPONDYLOARTHRITIS AND PSORIATIC ARTHRITIS}

L. Santo $^{1}$, F. D'Onofrio ${ }^{2}$, M.G. Anelli ${ }^{3}$, N. Maruotti ${ }^{2}$, R. Bucci ${ }^{4}$, A. Semeraro ${ }^{5}$, C. Zuccaro ${ }^{6}$, G. Carlino ${ }^{7}$, A. Marsico ${ }^{5}$, L. Quarta ${ }^{8}$, O. Casilli $^{8}$,

P.C.F. Falappone ${ }^{9}$, F. lannone ${ }^{3}{ }^{1}{ }^{1}$ O.U. of Rheumatology, ASL Barletta, Bari;

${ }^{2}$ UOC Reumatologia Universitaria, University of Foggia, Foggia; ${ }^{3}$ DETO -

Rheumatoly Unit, University of Bari, Bari; ${ }^{4}$ Rheumatology Hospital Unit, AOU

Foggia, Foggia; ${ }^{5}$ O.U. of Rheumatology, ASL Taranto, Taranto; ${ }^{6}$ Ambulatorio Reumatologia, Ospedale "Perrino", Brindisi, ${ }^{7}$ ASL LECCE - DSS Casarano and Gallipoli, Rheumatology Service, Casarano; ${ }^{8} \mathrm{OU}$ of Rheumatology, "V.Fazzi" Hospital, Lecce; ${ }^{9}$ Ambulatorio Reumatologia, Ospedale di Mesagne, Mesagne, Italy

Background: In real-life world settings, failure of a first TNF-inhibitor (TNFi) put rheumatologists against a crossroad to choose a further TNFi or a biologic drug with a different mechanism of action.

Objectives: Aim of this study was to assess effectiveness of golimumab (GOL) as second line drug after failure of a first TNFi as treatment of patients affected with rheumatoid arthritis (RA), psoriatic arthritis (PsA), or axial-spondyloarthritis (Ax-SpA).

Methods: GOAREL is a prospective cohort of patients starting GOL in communitybased care rheumatology centers in Apulia (south Italy) since 2013. Of 494, we selected 368 patients (RA n.73, PsA n.168, and n. Ax-SpA 127) commencing GOL as first ever biological (n.206, 56\%) or second treatment (n.161, 44\%) after inadequate response to a first TNFi (adalimumab (ADA, n.51), etanercept (ETA, n.81), or infliximab (IFX, n.29). Three patients failing certolizumab were excluded. Primary endpoint was to compare the drug retention rate of biological naïve and TNFi inadequate responders (TNFi-IR) patients on treatment with GOL. In addition, drug retention of second line GOL patients according to the firs TNFi was assessed. Drug survival was estimated by Kaplan-Meier life table analysis. Estimates hazard ratios (HRs) of 2- years drug discontinuation adjusted for demographics, type of disease, disease characteristics, body mass index, co-therapy with glucocorticoids or methotrexate, and prior TNFi were computed by backward selection Cox-regression model.

Results: 2-year drug survival on GOL of naïve and TNF-IR patients was not significantly different (Figure 1). Mean survival time was 20.0 months $(95 \% \mathrm{Cl}$ 18.9-21.0) for naïve and 20.4 months $(95 \% \mathrm{Cl} 19.3-21.6)$ for TNFi-IR patients. Likewise, drug retention rates on GOL of TNFi-IR patients subdivided by previous TNFi was not significantly different and similar to naïve patients (Figure 1). Mean survival time was 19.0 months $(95 \% \mathrm{Cl} 16.7-21.4)$ for prior-ADA, 20.5 months $(95 \% \mathrm{Cl} 18.9-22.1)$ for prior-ETA, and 22.0 months (95\% Cl 19.6-24.3) for prior-IFX. Multiple Cox-regression model showed gender female as the only independent factor positively associated to the risk of GOL discontinuation (HR $2.5,95 \%$ Cl 1.5-4.2, p 0.0001).
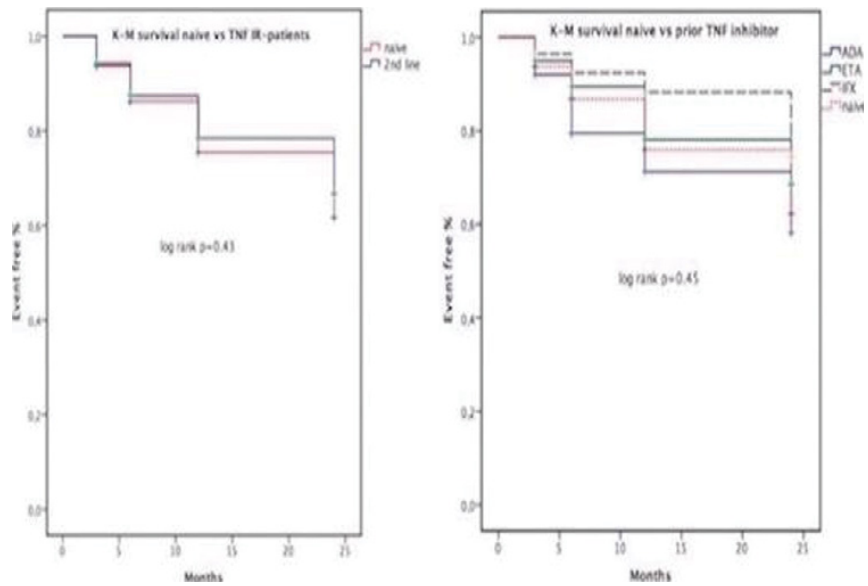

Figure 1

Conclusions: In real-life setting effectiveness of GOL seems to be similar in naïve or TNFi-IR patients with RA, PsA, and Ax-Spa. Furthermore, clinical outcomes were not influenced by the previous TNFi.

Disclosure of Interest: None declared

DOI: 10.1136/annrheumdis-2017-eular.3610

\section{AB0774 PREVALENCE, CLINICAL AND RADIOGRAPHIC CHARACTERISTICS OF SACROILITIS IN PATIENTS WITH PSORIASIS}

L. Stefanović ${ }^{1}$, D. Veljković ${ }^{2}$, E. Mahmutović ${ }^{3}$, V. Skakić ${ }^{4} .{ }^{1}$ Dom zdravlja Kraljevo; ${ }^{2}$ Odsek za sanitetsko obezbeenje, Odred Žandarmerije, Kraljevo, ${ }^{3}$ Državni Univerzitet Novi Pazar, Departman za biomedicinske nauke, Novi Pazar; ${ }^{4}$ Institute Niska Banja, Nis, Serbia

Background: Psoriasis is a skin disorder that is associated with arthritis.
Sacroiliac joint involvement is considered to be less frequent than the other types of psoriatic arthritis.

Objectives: im of the study was to investigate the prevalence of sacroilitis in patients with psoriasis (Ps) in region of Kraljevo, Novi Pazar and Niška banja.

Methods: A multicenter, noninterventional, retrospective, cross-sectional study was conducted at 3 care centers in region of Kraljevo, Novi Pazar and Niška banja. Diagnosis of sacroilitis was based on clinical and antero-posterior pelvic $X$-rays Prevalence of sacroilitis and its clinical and radiologic characteristics were examined.

Results: Sacroilitis was documented in 24/100 (24\%) patients with Ps. There was no significant difference in average age between Ps patients without sacroilitis $(47,83)$ and Ps patients with sacroilitis $(49,9)$. Sacroiliitis appeared to be unilateral in $12,5 \%$ and bilateral in $87.5 \%$ of patients. Ps preceded sacroilitis in $62,50 \%$ and sacroilitis preceded Ps in $29,17 \%$ of cases; concomitant onset of Ps and sacroilitis was present in $8,33 \%$. Peripheral arthritis was found in $67,89 \%$ patients with sacroilitis.

Conclusions: The prevalence of sacroilitis and related spondylitis is high in patient with Ps. We found predominantly bilateral sacroilitis which is characteristic of ankylosing spondylitis. This is in contrast to present knowledge about the association of psoriasis and sacroiliitis. In $68 \%$ sacroilitis patients we found associated peripheral arthritis.

Disclosure of Interest: None declared

DOI: 10.1136/annrheumdis-2017-eular.6737

\section{AB0775 UNDERESTIMATED AXIAL AND ENTHESIAL INVOLVEMENT IN PATIENTS WITH PSORIATIC ARTHRITIS IN A RUSSIAN DERMATOLOGICAL DAILY PRACTICE: COMPARED WITH RHEUMATOLOGICAL PRACTICE}

M. Chamurlieva, E. Loginova, T. Korotaeva. Nasonova Research Institute of Rheumatology, Moscow, Russian Federation

Background: Psoriatic arthritis (PsA) is frequently underdiagnosed by dermatologists due to it's heterogeneous clinical manifestations such as peripheral arthritis, dactylitis, spondylitis and enthesitis. For the correct early diagnosis, choice of treatment and for better outcomes proper evaluation of all symptoms is required. Objectives: to compare the definition of the main clinical symptoms of PsA by dermatologists and rheumatologists in daily clinical practice.

Methods: 103 pts (male-47/female-56) with different forms of plaque psoriasis ( $\mathrm{PsO}$ ), mean age $44 \pm 13.69$ years (yrs.), mean psoriasis duration $10.7 \pm 10.2 \mathrm{yrs}$ mean PASI $5.05 \pm 1.23$ were included. In dermatological clinic, all pts completed a PEST questionnaire and underwent clinical evaluation by a dermatologists in order to identify the main clinical symptoms of PsA such as peripheral arthritis, dactylitis, spondylitis and enthesitis. Later all pts were subsequently evaluated by rheumatologists to confirm/exclude the diagnosis of PsA based on CASPAR criteria and underwent standard clinical examination to identify the same symptoms - peripheral arthritis, dactylitis, spondylitis (based on inflammatory back pain (IBP) ASAS criteria) and enthesitis (based on Leeds Enthesial Index (LEI) plus Plantar Fascia (PF). M $\pm m, \%$, t-test were peformed. All $p<0.05$ were considered to indicate statistical significance.

Results: 61 out of 103 pts with PsO (59.2\%) had PsA based on rheumatological evaluation and CASPSR criteria. Dermatologists diagnosed peripheral arthritis in significantly less cases compared to rheumatologists: in $15(24.6 \%)$ and in $35(57.4 \%)$ out of 61 pts $(p<0.001)$ accordingly. No significant difference was seen in clinical evaluation of dactylitis by dermatologists or rheumatologists in $37(60.7 \%)$ and in $40(65.6 \%)$ out of 61 pts accordingly $(p=0.32)$. Heel pain was noted by dermatologists in 32 out of 61 pts $(52.5 \%)$ according to PEST questionnaire. Dermatologists could not find enthesitis according to LEI. Rheumatological examination based on LEI scale identified lateral epicondyles in 11 out of 61 pts $(18 \%)$, enthesitis of medial femoral condyles in 8 out of 61 pts $(13.1 \%)$, enthesitis of Achilles tendon insertions - in 25 out of 61 pts (41\%). Enthesitis of PF were observed in 15 out of 61 pts $(24.6 \%)$. Dermatologists noted back pain using PEST questionnaire in 30 out of 61 pts (49.2\%). IBP based on ASAS criteria was not detected by a dermatologists in any case. In these 30 pts having back pain IBP was diagnosed by a rheumatologists in $21(70 \%)$ cases; and in the rest 9 out of 30 pts $(30 \%)$ mechanical back pain was observed. On the basis of clinical examination tendinitis was not noted by dermatologists, while rheumatologists found hand tendinitis in 13 out of 61 pts (21.3\%).

Conclusions: Perypheral arthrtitis, axial and enthesial involvement were underestimated by dermatologists using PEST screening questionnaire, because it does not cover these symptoms in detail. ASAS criteria for IBP and standard enthesitis assessment should be implemented into Russian dermatological clinical practice. In order to improve early PsA diagnosis in dermatological practice, interdisciplinary educational training programmes and collaboration with rheumatologists are needed.

Disclosure of Interest: None declared

DOI: 10.1136/annrheumdis-2017-eular.2771 